\title{
THE
}

\section{Evidence for activated Lck protein tyrosine kinase as the driver of proliferation in acute myeloid leukemia cell, CTV-1}

\author{
Li Li \\ University of Rhode Island \\ Yixin Cui \\ University of Rhode Island \\ Jinyan Shen \\ University of Rhode Island \\ Hannah Dobson \\ University of Rhode Island

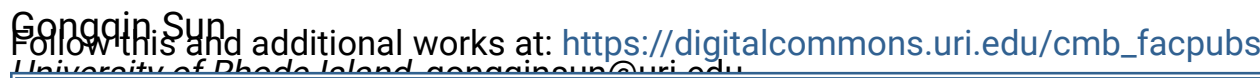 \\ The University of Rhode Island Faculty have made this article openly available. \\ Please let us know how Open Access to this research benefits you.
}

This is a pre-publication author manuscript of the final, published article.

Terms of Use

This article is made available under the terms and conditions applicable towards Open Access

Policy Articles, as set forth in our Terms of Use.

\section{Citation/Publisher Attribution}

Li, L., Cui, Y., Shen, J., Dobson, H., \& Sun, G. (2019). Evidence for activated Lck protein tyrosine kinase as the driver of proliferation in acute myeloid leukemia cell, CTV-1. Leukemia Research, 78, 12-20. doi:

10.1016/j.leukres.2019.01.006

Available at: https://doi.org/10.1016/j.leukres.2019.01.006

This Article is brought to you for free and open access by the Cell and Molecular Biology at DigitalCommons@URI. It has been accepted for inclusion in Cell and Molecular Biology Faculty Publications by an authorized administrator of DigitalCommons@URI. For more information, please contact digitalcommons-group@uri.edu. 
Research

Elsevier Editorial system(tm) for Leukemia

Manuscript Draft

Manuscript Number: LR-D-18-00519R3

Title: Evidence for activated Lck protein tyrosine kinase as the driver of proliferation in acute myeloid leukemia cell, CTV-1

Article Type: Original Article

Section/Category: Original Article

Keywords: acute myeloid leukemia; Lck protein tyrosine kinase; driver mutations; driver of proliferation; CTV-1

Corresponding Author: Dr. Gongqin Sun,

Corresponding Author's Institution: University of Rhode Island

First Author: Li Li

Order of Authors: Li Li; Yixin Cui; Jinyan Shen; Hannah Dobson; Gongqin Sun

Abstract: Acute myeloid leukemia (AML) is a heterogeneous group of fast growing cancers of myeloid progenitor cells, for which effective treatments are still lacking. Identification of signaling inhibitors that block their proliferation could reveal the proliferative mechanism of a given leukemia cell, and provide small molecule drugs for targeted therapy for AML. In this study, kinase inhibitors that block the majority of cancer signaling pathways are evaluated for their inhibition of two AML cell lines of the M5 subtypes, CTV-1 and THP-1. While THP-1 cells do not respond to any of these inhibitors, CTV-1 cells are potently inhibited by dasatinib, bosutinib, crizotinib, A-770041, and WH-4-23, all potent inhibitors for Lck, a Src family kinase. CTV-1 cells contain a kinase activity that phosphorylates an Lck-specific peptide substrate in an Lck inhibitor-sensitive manner. Furthermore, the Lck gene is overexpressed in CTV-1, and it contains four mutations, two of which are located in regions critical for Lck negative regulation, and are confirmed to activate Lck. Collectively, these results provide strong evidence that mutated and overexpressed Lck is driving CTV-1

proliferation. While Lck activation and overexpression is rare in AML, this study provides a potential therapeutic strategy for treating patients with a similar oncogenic mechanism. 


\section{Highlights}

The proliferation of CTV-1 AML cells are potently inhibited by Lck kinase inhibitors CTV-1 lysate contains Lck kinase activity

Lck gene in CTV-1 is over-expressed, and contains four mutations

Two of the mutations disrupt negative regulation to activate Lck

The first natural cell line driven by a constitutively activated Src family kinase 
Evidence for activated Lck protein tyrosine kinase as the driver of proliferation in acute myeloid leukemia cell, CTV-1 


\begin{abstract}
Acute myeloid leukemia (AML) is a heterogeneous group of fast growing cancers of myeloid progenitor cells, for which effective treatments are still lacking. Identification of signaling inhibitors that block their proliferation could reveal the proliferative mechanism of a given leukemia cell, and provide small molecule drugs for targeted therapy for AML. In this study, kinase inhibitors that block the majority of cancer signaling pathways are evaluated for their inhibition of two AML cell lines of the M5 subtypes, CTV-1 and THP-1. While THP-1 cells do not respond to any of these inhibitors, CTV-1 cells are potently inhibited by dasatinib, bosutinib, crizotinib, A-770041, and WH-4-23, all potent inhibitors for Lck, a Src family kinase. CTV-1 cells contain a kinase activity that phosphorylates an Lck-specific peptide substrate in an Lck inhibitor-sensitive manner. Furthermore, the Lck gene is over-expressed in CTV-1, and it contains four mutations, two of which are located in regions critical for Lck negative regulation, and are confirmed to activate Lck. Collectively, these results provide strong evidence that mutated and overexpressed Lck is driving CTV-1 proliferation. While Lck activation and overexpression is rare in AML, this study provides a potential therapeutic strategy for treating patients with a similar oncogenic mechanism.
\end{abstract}




\section{Introduction}

Acute myeloid leukemia (AML) is a heterogeneous group of fast growing cancers of myeloid progenitor cells. Based on the cell type and the stage at which the cellular development is disrupted, AML is divided into eight subtypes, M0 through M7 [1]. Multiple genetic mutations are known to play key roles in the development of AML [2, 3]. These mutations can inactivate transcription factors, such as AML1/ETO [4], CBF/SMMHC [5, 6], PML-RARa [7], or MLL fusion proteins $[8,9]$, to disrupt differentiation $[10,11]$, confer the cell sustained proliferation and an escape from apoptosis [11], or affect epigenetic modifications [3, 11, 12].

Despite a general understanding of AML genetic landscape, AML is notoriously heterogeneous, and the driver mutations in most AML cell lines have not been identified. With the exception of FLT3 inhibitors [13] in clinical development, targeted and specific therapy is still not available for most AML patients. Treatment of AML patients still mostly relies on the anthracycline-cytarabine regimen designed more than four decades ago [14].

An M5 AML patient has more than 20\% blasts in the bone marrow, and more than $80 \%$ of the blasts are of monocytic lineage [1]. Some chromosomal abnormalities affecting MLL, a global transcription regulator, have been well documented in M5 [15-16]. What signaling mechanisms sustain M5 cell proliferation is not clear. Treatment of M5-AML relies on traditional chemotherapy and bone marrow transplantation.

Lck is a $56 \mathrm{kD}$ protein tyrosine kinase in the Src family, and it is most commonly expressed in T lymphocytes [17]. It associates with the cytoplasmic tails of T cell co-receptors, CD4 and CD8. Engagement of T-cell surface receptors with antigen presented by MHC activates Lck, which then phosphorylates substrates, including CD3, $\zeta$ chain of TCR and ZAP-70, leading to T cell activation [18]. To play this normal physiological role, Lck is under tight regulation by 
autophosphorylation (Tyr394, activation), and Csk phosphorylation (Tyr505, inactivation) [19].

Like other members in the Src family, constitutively activated Lck caused by mutation is oncogenic [20-21], even though there is no report of Lck mutants being responsible for naturally occurring cancers or cancer cell lines.

In this study, we use small molecule inhibitors against various oncogenic protein tyrosine kinases to probe for the key drivers of proliferation in two M5 AML cells, CTV-1 [23-24] and THP-1 [25-26]. The inhibition profiling suggests that Lck protein tyrosine kinase is the key oncogenic driver of CTV-1 cell proliferation, which is confirmed by molecular and mutagenic analyses. In contrast, the THP-1 cells do not rely on any signaling pathways tested to sustain its proliferation. These results shed light on the proliferative mechanism of an M5 cell line of AML. AML cells rarely express Lck, and there is evidence that the overexpression and activation of Lck in CTV-1 cells may be due to lineage switching from T-cell acute lymphoblastic leukemia to AML. This study provides a foundation for developing therapeutic strategies against this subtype of AML.

\section{Materials and Methods}

\subsection{Cell culture and treatment}

The AML cell lines CTV-1 (purchased from DSMZ, Braunschweig, Germany) and THP1 (purchased from ATCC, Manassas, VA, USA) were grown in RPMI1640 containing 10\% FBS and $1 \%$ Penicillin - streptomycin at $37^{\circ} \mathrm{C}$ in humid atmosphere containing $5 \% \mathrm{CO}_{2}$. Kinase inhibitors were purchased from Selleckchem (Munich, Germany), LC Laboratories (Woburn, MA, USA) or AdooQ Bioscience (Irvine, CA, USA). Biolog Redox Dye Mix MA or MB (Biolog Inc. Cabot Blvd. Hayward CA, USA) was used to stain the cells for viability assays. 
Cells were plated onto 96-well plates at $5 \times 10^{4}$ cells/well, and were incubated with 16 different concentrations $(0.0006 \mu \mathrm{M}-20 \mu \mathrm{M})$ of each kinase inhibitor for $72 \mathrm{~h}$. The viable cells were determined by staining the cells with Biolog Redox Dye Mix MA or MB, and measuring the absorbance of the water soluble formazan product from the dye reduction using a VersaMax Tunable Microplate Reader at 590 and $750 \mathrm{~nm}$. The absorbance values of A590-A750 were taken as indicator of cell viability. Each experiment was done in triplicate, and repeated at least three times independently. The average and standard deviation for each treatment were calculated in Microsoft Excel. Outlier readings judged as inconsistent with other readings in the same treatment were removed.

\subsection{The expression level of Lck protein in the leukemia cell lines}

Approximately $1.25 \times 10^{8}$ CTV-1, THP-1and GDM-1 cells were lysed in $200 \mu 1$ lysis buffer (Tris-HCl 50mM, NaCl 150mM, EDTA 1mM, Triton-X-100 0.05\%). The lysates were mixed with an equal volume of $2 \mathrm{X}$ SDS-PAGE loading buffer, and heated for 10 minutes at $95^{\circ} \mathrm{C}$. After quick spin down, the denatured lysates $(10 \mu \mathrm{l})$ were loaded into each well on the ready-gel (Bio-Rad, CA, 94547, USA) for electrophoresis. The fractionated proteins were transferred onto a nitrocellulose membrane using semi-dry transfer cell (Bio-Rad, CA 94547, USA), and the membrane was blocked for 1 hour using 5\% milk. The membrane was rinsed 3 times using Tris-buffered saline with Tween 20 (TBST), and then incubated with an Lck rabbit monoclonal antibody (Cell Signaling, Danvers, MA) at $4^{\circ} \mathrm{C}$ overnight with gentle shaking. After washing three times with TBST for 3 min each, the membrane was incubated with a secondary antibody (anti-rabbit IgG, Sigma, Billerica, MA 01821) for 1 hour. After rinsing 3 times with TBST for 3 min each, the secondary antibody attached to the membrane was detected 
by SuperSignal west pico (SuperSignal $^{\mathrm{TM}}$ Pico Chemiluminescent Substrate (Thermo Scientific $\left.{ }^{\mathrm{TM}}\right)$. The images were generated using conventional X-ray films. $\beta$-Actin detected by a monoclonal antibody (Cell Signaling, Danvers, MA) was used as loading control.

\subsection{Lck activity in cell lysates}

CTV-1 cells were harvested and washed twice in phosphate buffered saline (PBS). Approximately $1.25 \times 10^{8} \mathrm{CTV}-1$ cells were lysed in $200 \mu \mathrm{l}$ lysis buffer (Tris-HCl $50 \mathrm{mM}, \mathrm{NaCl}$ $150 \mathrm{mM}$, EDTA $1 \mathrm{mM}, 0.005 \%$ Triton-X-100). The cell lysate $(10 \mu \mathrm{l})$ and $10 \mu \mathrm{l}$ kinase assay buffer was added to $20 \mu \mathrm{l} \mathrm{Lck}$ peptide substrate, GST-AEEEIYGVLFAKKKK (1 mg/ml). An aliquot of $10 \mu \mathrm{l}$ of ATP cocktail (final concentration: ATP $0.2 \mathrm{mM}, 12 \mathrm{mM} \mathrm{MgCl}$ ) was added to initiate the reaction. When the effect of inhibitors was determined, the kinase inhibitor, dasatinib or A-770041, was included in the kinase assay buffer (final concentration $=1 \mu \mathrm{M}$ ). After 30 min reaction, the reactions were mixed with equal volume of SDS-PAGE loading buffer and prepared for SDS-PAGE and Western Blotting. Tyrosine phosphorylation on Lck peptide substrate and cellular proteins was detected using a mouse monoclonal antibody against phosphotyrosine, and a secondary anti-mouse IgG antibody (Sigma, 3050 Spruce St. St. Louis, MO). Western blotting was performed as described above.

\subsection{Kinase activity assay of wt Lck and Lck mutants in vitro}

The wt human Lck coding gene was cloned into pGEX-4T-1, and the wt Lck enzyme was expressed as a GST fusion protein. Lck mutants, each containing a mutation found in CTV-1 cells were generated via Quikchange using wt-Lck in pGEX-4T-1 plasmid as template. The primers used for generating the Lck mutants are listed in Table 1. 
All constructs were confirmed by DNA sequencing. The wt and each of the Lck mutants were expressed in DH5 $\alpha$ bacterial cells, and purified by glutathione affinity chromatography as previously described [27]. Briefly, the DH5 $\alpha$ bacterial cells harboring the pGEX-Lck or mutant were inoculated in $10 \mathrm{ml} \mathrm{LB}$ medium for overnight culture at $37^{\circ} \mathrm{C}$. The overnight culture was mixed with $500 \mathrm{ml}$ fresh LM medium, and cultured at room temperature until the OD600 reached 1. The Lck expression was then induced by $0.5 \mathrm{mM}$ isopropyl $\beta-\mathrm{D}-1$ thiogalactopyranoside (IPTG) for 4 hours. The cells were harvested by centrifugation. The four Lck mutants generated are P232_W233insQKP, A353V, P447L, and A500T. GST-Lck mutants were purified on ice as previously described [2]. Protein concentrations were determined by Bradford protein assay using bovine serum albumin as a standard.

\subsection{The activity of wild type and mutants of Lck}

For analysis of Lck and mutant activities, we measured the phosphorylation of the Lck peptide substrate using Western blot method. A standard assay reaction of $50 \mu \mathrm{L}$ contained the purified kinase $(10 \mu \mathrm{l})$, the peptide substrate $(20 \mu \mathrm{l}$, final concentration $1 \mathrm{mg} / \mathrm{ml})$, ATP cock tail $(10 \mu \mathrm{l})$, and the kinase assay buffer (75 mM 4-(2-hydroxyethyl)piperazine-1-propanesulfonic

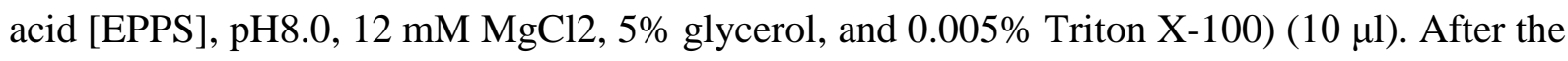
reaction at room temperature for $30 \mathrm{~min}, 40 \mu \mathrm{l}$ reactions were mixed with equal volumes of $2 \mathrm{X}$ loading SDS-PAGE loading buffer. The phosphorylation of the peptide substrate was determined by Western blotting using a monoclonal antibody against phosphotyrosine as described earlier. The band density was measured using the ImageJ software (https://imagej.nih.gov/ij/download.html). 


\section{Results}

3.1. Protein tyrosine kinase inhibitors are used to probe the oncogenic signaling of CTV-1 and THP-1 cells

To identify the drivers of proliferation in the two M5 AML cell lines, CTV-1 and THP-1, we determined their sensitivity to a panel of PTK inhibitors. CTV-1 is a human monocytic leukemia cell line established from a 40 yr-old male patient with relapsed acute monoblastic leukemia [23-24]. THP-1 is a monocytic cell line established from a 1-yr old male patient of acute monocytic leukemia [25]. CTV-1 has been barely studied, while THP-1 has been extensively characterized as a model cell line for studying differentiation of monocytes and macrophages [26]. The proliferative driver for either cell line has not been identified.

In order to determine what signaling pathways are important for the proliferation of these cells, 10 PTK inhibitors that collectively target most of the oncogenic signaling pathways are selected (Table 2). Eight of the inhibitors have been tested for the binding affinities toward most of the protein kinases in the human kinome (http://lincs.hms.harvard.edu/kinomescan/), and they bind to the target PTKs with in vitro $K_{d}$ value below $20 \mathrm{nM}$. Two of the inhibitors, BMS-754807 and BGJ398, have not been tested against the kinome, but their specificities have been evaluated toward a large number of PTKs in the original studies. BMS-754807 specifically inhibits receptor PTKs in the insulin receptor family and Met [28-29], and BGJ398 inhibits receptor PTKs of the FGFR family [30]. Considering that insulin receptor, insulin-like growth factor receptor and FGFR kinases are potentially important oncogenic enzymes, these two inhibitors are also included in this study. There are 33 cancer census PTK genes [31] distributed in PTK families, such as Src, Abl, PDGFR, EGFR, FGFR, etc. The only cancer census PTK that is not inhibited by at least one of these inhibitors is EphA7. If any of these target PTKs is important for 
the proliferation of CTV-1 or THP-1, the proliferation of the cell line should be inhibited by the respective inhibitors.

\subsection{Drug sensitivity analysis suggests a Src family kinase, Lck, is essential for the} proliferation of CTV-1 cells

The dose responses of both cell lines to each inhibitor at 16 concentrations from $0.6 \mathrm{nM}$ to $20 \mu \mathrm{M}$ were determined (Fig. 1). Seven inhibitors did not achieve 50\% inhibition of CTV-1 proliferation even at $20 \mu \mathrm{M}$ (neratinib, sunitinib and BMS754807), or displayed $\mathrm{IC}_{50}$ values between 1 and $5 \mu \mathrm{M}$ (BGJ398, NVP-TAE684, imatinib and linifanib) (Fig. 1). These results suggest that their intended targets, the kinases in the EGFR, PDGFR, and insulin receptor families, among others, do not play significant roles in driving CTV-1 proliferation. Based on this result, the following kinase families are eliminated: EGFR, FGFR, PDGFR, Insulin receptor, IGF-1R, and Abl. Four inhibitors, BGJ398, NVP-TAE684, imatinib and linifanib displayed IC $_{50}$ values between 1 and $5 \mu \mathrm{M}$. Because these inhibitors bind to their intended PTK targets with $K_{d}$ values below $20 \mathrm{nM}$, the $\mathrm{IC}_{50}$ values above $1 \mu \mathrm{M}$ are likely due to interactions with non-specific targets. For example, imatinib binds to kinases in the Abl family and some members in the PDGFR family with $K_{d}$ values below $15 \mathrm{nM}$. If these Abl and PDGFR kinases are important for CTV-1 proliferation, imatinib would likely have inhibited CTV-1 proliferation much more potently. It has been reported that imatinib inhibits the proliferation of numerous cell lines dependent on Philadelphia Chromosome with $\mathrm{IC}_{50}$ below $600 \mathrm{nM}$ [32].

Three inhibitors displayed $\mathrm{IC}_{50}$ values below $1 \mu \mathrm{M}$ : dasatinib $(13 \mathrm{nM})$, bosutinib (50 nM) and crizotinib (251 nM) (Fig. 1A). These $\mathrm{IC}_{50}$ values are likely the result of the inhibitors blocking certain high affinity target(s) that is(are) essential for the proliferation of the CTV-1 
cells. Dasatinib and bosutinib most potently inhibit PTKs of the Src and Abl families, two of the most common oncoprotein families. Both inhibitors also display differing levels of inhibition toward other PTKs, such as members in the Abl, BRK, and PDGFR families. Kinases of the PDGFR family are eliminated as potential drivers for CTV-1 proliferation because CTV-1 proliferation was not inhibited by sunitinib and linifanib. Abl1 and Abl2 also do not play an important role in the proliferation of CTV-1 because CTV-1 proliferation is not potently inhibited by imatinib (Fig. 1B). The elimination of these targets leaves the Src family kinases as the most plausible candidates for sustaining the proliferation of CTV-1. Crizotinib also inhibited CTV-1 proliferation with an $\mathrm{IC}_{50}$ of $251 \mathrm{nM}$. Crizotinib is best known as a Met/Alk kinase inhibitor (Table 2), with respective $K_{d}$ 's of $2.1 \mathrm{nM}$ and $7.8 \mathrm{nM}$, but it also binds to Src family kinase, Lck, with a $K_{d}$ of $30 \mathrm{nM}$ (http://lincs.hms.harvard.edu/kinomescan/). Interestingly, crizotinib has a much higher $K_{d}$ for Src at $560 \mathrm{nM}$. Alk is also a target of NVP-TAE684, and Met is also a target of BMS-754807, and both of these inhibitors did not potently inhibit CTV-1 proliferation. These considerations eliminate Met and Alk, and leave Lck as the most logical target for crizotinib. Thus, all three potent inhibitors of CTV-1 proliferation have one thing in common: they all inhibit Lck, suggesting that Lck is the most likely driver for CTV-1 proliferation.

Although both THP-1 and CTV-1 are M5 AML cells, their responses to the PTK inhibitors are remarkably different. THP-1 is not inhibited by any of the inhibitors (Fig. 1), indicating that THP-1 cells do not rely on any of the probed pathways for proliferation. More specifically, while Lck appears to be the driver of CTV-1 proliferation, THP-1 cells do not rely on Lck for proliferation.

\subsection{CTV-1 is inhibited by Lck-specific inhibitors}


The Src family contains eight PTKs with similar structures and similar responses to most kinase inhibitors [33-34]. The inhibition of CTV-1 proliferation by dasatinib and bosutinib does not provide any clue as to which SFK kinase might be driving CTV-1 proliferation. The inhibition by crizotinib, however, favors Lck as the likely proliferative driver because Lck is the only Src family kinase that binds crizotinib relatively tightly $\left(K_{d}=30 \mathrm{nM}\right)$. To further confirm that Lck is responsible for CTV-1 proliferation, we determined if CTV-1 proliferation is sensitive to Lck-specific inhibitors. A-770041 is an inhibitor able to differentiate $\mathrm{Lck}\left(\mathrm{IC}_{50}=147\right.$ $\mathrm{nM})$ from other Src family kinases $\left(\mathrm{Src} \mathrm{IC}_{50}=9.1 \mu \mathrm{M}\right.$, Fyn $\mathrm{IC}_{50}=44.1 \mu \mathrm{M}$, Fgr IC $_{50}=14.1 \mu \mathrm{M}$, Hck $\mathrm{IC}_{50}=1.22 \mu \mathrm{M}$, Lyn $\left.\mathrm{IC}_{50}=1.18 \mu \mathrm{M}\right)$ [35-36]. While these data suggest that A-770041 is a specific inhibitor against Lck, it has not been tested against the complete kinome, it is possible that it could inhibit other PTKs.

CTV-1 is indeed very sensitive to A-770041, with an $\mathrm{IC}_{50}$ of $224 \mathrm{nM}$, with near complete inhibition of proliferation reached at $400 \mathrm{nM}$ (Fig. 2A). This potent $\mathrm{IC}_{50}$ provides the strongest evidence that Lck, and not Src, is driving CTV-1 proliferation. The potent sensitivity of CTV-1 cells to A-770041 forms a direct contrast to another AML cell line, GDM-1. As shown in Fig. 2B, GDM-1 cells are extremely sensitive to dasatinib $\left(\mathrm{IC}_{50}=10 \mathrm{nM}\right)$, but much less sensitive to A770041 with an $\mathrm{IC}_{50}$ of approximately $6 \mu \mathrm{M}$, demonstrating the differing specificity of A-770041 and dasatinib. WH-4-023 is another potent inhibitor toward Lck [37], with a reported IC $_{50}$ of 0.6 nM. Based on the initial characterization of this inhibitor against a small panel of PTKs, it inhibits Lck and Src with similar $\mathrm{IC}_{50}$, at least 100 times better than other non-Src family kinases [37]. CTV-1 proliferation is also inhibited by WH-4-023 with an $\mathrm{IC}_{50}$ of $700 \mathrm{nM}$. The unique sensitivity of CTV-1 proliferation toward A-770041 provides further evidence for Lck as the driver of CTV-1 proliferation. 


\subsection{Lck in CTV-1 contains several mutations and is over expressed in CTV-1 cells}

We then examined the genetic information of CTV-1 available from the Catalogue of Somatic Mutations in Cancer (https://cancer.sanger.ac.uk/cell_lines/sample/overview?id=753548) [38]. CTV-1 contains 3700 mutated genes and 151 mutated cancer census genes. Based on the genomic information alone, it is impossible to attribute the growth properties to any of these mutations. In comparison, THP-1 contains only 345 mutated genes and 19 mutated cancer census genes. Among the 8 Src family kinases, Lck in CTV-1 contains 4 mutations (P232_W233insQKP, P447L, A353V, and A500T), and its mRNA is also over expressed, with a Z-score of 3.88. This expression level makes CTV-1 the highest expresser of Lck among all the cells in which Lck expression data is available in the database. In contrast, Lck is not overexpressed in THP-1, nor does it contain any mutations. Interestingly, Src also contains one mutation in CTV-1, Q222H. This genomic information suggests that Lck may be activated by mutation in addition to its over-expression, consistent with the drug sensitivity data that suggest that Lck drives CTV-1 proliferation.

To confirm that CTV-1 over-expresses Lck at the protein level, as suggested by the elevated mRNA level, we determined its protein expression level in CTV-1 and THP-1 by Western blotting. In this experiment, we also included another AML cell line, GDM-1 [39]. As shown in Fig. 3B, Lck is readily detectable in CTV-1, but undetectable in THP-1, nor in GDM-1. The lack of Lck expression in THP-1 and GDM-1 is consistent with the current understanding of Lck tissue distribution. Lck is known to be specifically expressed in T-cells [17], and is not known to be expressed in other cell types. In this regard, the lack of Lck expression in THP-1 and GDM-1 is consistent with their myeloid origin, while the Lck over-expression in CTV-1 is 
abnormal and likely related to its oncogenic signaling. It is established that Lck overexpression is able to cause tumorigenesis [20-22].

\subsection{CTV-1 contains a kinase activity that phosphorylates an Lck peptide substrate in an Lck} inhibitor sensitive manner

We next compared the kinase activity in CTV-1 and THP-1 using an Lck specific peptide substrate, EEEIYGVLF. This peptide substrate was previously identified using a random library screening [40]. The peptide substrate sequence is fused to the C-terminus of glutathione S transferase and purified by glutathione affinity chromatography, and then used as an Lck substrate. CTV-1 lysate was incubated with the peptide substrate in the presence of ATP-Mg in a kinase assay buffer, and the phosphorylation of the peptide was determined by Western blotting using a monoclonal antibody against phosphotyrosine. As shown in Fig. 3A, incubation of CTV1 cell lysate with ATP resulted in Tyr-phosphorylation of extensive number of proteins. When the peptide substrate was included, the peptide was phosphorylated, indicating that CTV-1 lysate contains a protein tyrosine kinase activity that is able to phosphorylate this peptide substrate. Furthermore, both dasatinib and A-770041 at $1 \mu \mathrm{M}$ completely blocked the phosphorylation of this peptide substrate. The inhibitors did not significantly affect the presence of other phosphorylated proteins, indicating that phosphorylation of majority of the cellular proteins is not catalyzed by a kinase sensitive to these inhibitors. The inhibitory specificity of A-770041 for Lck suggests that the peptide substrate is indeed phosphorylated by Lck. The THP-1 lysate was also used in a similar experiment as a control. To our surprise, THP-1 also contains a kinase activity that is able to phosphorylate the peptide substrate (Fig. 3B). However, this kinase activity is not sensitive to dasatinib or A-770041, indicating that a non-Lck kinase activity in 
THP-1 is also able to phosphorylate this substrate. The presence of a non-Lck kinase activity that was able to phosphorylate the peptide substrate was not expected, but not too surprising. Protein tyrosine kinases are notoriously lacking in specificity toward peptide substrates, and many PTKs are able to phosphorylate similar peptide substrates. These above results combined further demonstrate that CTV-1 proliferation is indeed driven by activated Lck activity in the cell.

\subsection{Mutations in CTV-1 Lck activate its kinase activity}

As noted earlier, Lck in CTV-1 contains four mutations, P232_W233insQKP, P447L, A353V, and A500T. Because there are two copies of the Lck gene in CTV-1, it is not clear if all four mutations are present in one copy or distributed in both alleles. Examination of the four mutations in the context of Lck regulation suggests a clear mechanism for at least two of these mutations to activate Lck. Src family kinases are negatively regulated by domain-domain interactions between the catalytic domain and the regulatory SH3 and SH2 domains [33-34]. This negative regulation is triggered by the binding of phosphorylated C-terminal tail Tyr residue (Tyr505 in Lck) to the SH2 domain, but it also requires the interactions of the SH2-catalytic domain linker with the SH3 domain and the catalytic domain [41-43]. One of the Lck mutations in CTV-1 is an insertion of three residues, ${ }^{232} \mathrm{QKP}$, in the $\mathrm{SH} 2$-catalytic domain linker. It is established that mutations in this region can abolish the negative regulation of Src, Lck and other Src family kinases [41, 44-45]. Another mutation is A500T, a residue located in the region that interacts with Csk which phosphorylates the c-terminal tail Tyr of Src family kinases [46-48]. These mutations would be expected to impair Lck inactivation and thus to activate Lck. Because full length Lck structure is not available and Src and Lck are similar in general structure and regulation, the regulated structure of Src [43] and the corresponding positions of the four Lck 
mutations are shown in Fig. 4A to illustrate the positions of these mutations. We determined the effects of each of the four mutations on the kinase activity of Lck by expressing, purifying and characterizing the wildtype and each of these mutant Lck variants. Purified GST-Lck variants were incubated with or without the peptide substrate under phosphorylating conditions, and the levels of peptide and Lck phosphorylation on Tyr was detected with a phosphor-Tyr antibody. Indeed, both mutations (P232_W233insQKP and A500T) activated Lck activity toward the peptide substrate, while all Lck mutants displayed similar levels of Lck autophosphorylation (Fig. 4B). Quantification of the band intensity of the phosphorylated Lck peptide substrate revealed that P232_W233insQKP and A500T increased Lck activity by 1.9-fold and 3.7 fold, respectively. These mutations and Lck over-expression in CTV-1 cells provide the molecular basis of Lck activation, which drives CTV-1 proliferation. It is well established that activated Lck and other Src family kinases are potent oncoproteins capable of transforming cells [20-22].

\section{Discussion}

The molecular mechanisms driving the proliferation of M5 subtypes of AML are mostly unknown. In this paper, we provide strong evidence that the proliferation of CTV-1 cell is driven by activated and over-expressed Lck. This conclusion is supported by three lines of evidence. First, CTV-1 proliferation is potently inhibited by five inhibitors that block Lck kinase activity, but not by other inhibitors that collectively inhibit majority of the protein tyrosine kinome, including most other cancer census PTKs. One of the potent inhibitors is A-770041, which inhibits Lck selectively even among Src family kinases. The fact that CTV-1 proliferation is only inhibited by Lck inhibitors indicates that Lck is specifically essential for CTV-1 proliferation. Second, Lck is over-expressed at the mRNA and the protein levels, and contains four mutations 
in CTV-1 cells. Two of the mutations are located in regions critical for Lck negative regulation and directly activate Lck kinase activity. Finally, CTV-1 lysate contains a kinase activity that phosphorylates an Lck peptide substrate and this activity is blocked by Lck-specific inhibitors. This work not only established a likely proliferative mechanism for CTV-1, it also provides a mechanistic basis for treating leukemia patients with a similar mechanism. Even though Src family kinases are well established oncogenes, CTV-1 is the first naturally occurring cell line in which a Src family kinase, activated by overexpression and mutation, is the main driver of proliferation.

While the results from this study strongly support Lck as the proliferative driver for CTV-1, inhibitor-based studies are invariably limited by the issue of specificity and off-target effects. Similarities among Src family kinases in their structure, biochemical function, and inhibitor response make it especially difficult to distinguish the contribution of one Src family kinase from that of another. For example, A-770041 has been shown to be a specific inhibitor for Lck $\left(\mathrm{IC}_{50}=147 \mathrm{nM}\right)$ over Src $\left(\mathrm{IC}_{50}=9.1 \mu \mathrm{M}\right)[35-36]$, but another study indicates that A-770041 is able to inhibit Src activation at sub- $\mu \mathrm{M}$ concentrations (49). Thus it is possible that Src may also contribute to the proliferation of CTV-1 cells. Furthermore, there is a possibility that some other kinases could also be blocked fully or partially by the inhibitors, which would contribute to the CTV-1 response to the inhibitors. Abl is another PTK that is also sensitive to several of the inhibitors that block CTV-1 proliferation, such as dasatinib and bosutinib. The insensitive response to imatinib by $\mathrm{CTV}-1\left(\mathrm{IC}_{50}=2.5 \mu \mathrm{M}\right)$ suggests that $\mathrm{Abl}$ is not a major contributor to CTV-1 proliferation, because BCR-Abl-dependent cell proliferation is inhibited by imatinib with IC 50 's between 80 and $600 \mathrm{nM}$ (32). However, other factors may render Abl-dependent cells less sensitive to imatinib, leaving Abl as a possible, albeit unlikely, candidate in CTV-1. Considering 
these possibilities, future genetic experiments targeting Lck and other Src family kinases are needed to ascertain that Lck is indeed the driver of CTV-1 proliferation.

\subsection{Kinome-wide drug sensitivity profiling can identify the signaling pathway that is essential for a cell's proliferation}

Because of the complexity of the cellular signaling network, the diversity of potential mechanisms driving the proliferation of a given cancer cell, and the large number of mutations a cancer cell may contain, determining the driver mutations sustaining a cell's proliferation is often a difficult task. That point is further underlined by the genomic information of CTV-1. With several thousand genes mutated in CTV-1, it is virtually impossible to predict what mutation or combination of mutations may be driving the proliferative phenotype. Predicting proliferative signaling mechanisms by proteomic information is also complicated because a large number of proteins often display altered expression profiles in cancer cells versus a normal cells. The current study of CTV-1 and THP-1 demonstrates that drug sensitivity profiling to a large number of signaling blockers can provide a direct and functional identification of the signaling pathway that drives the proliferation of a given cancer cell. The shortcoming of this approach is also made clear in this study by THP-1, which does not seem to be inhibited by any of the tested signaling drugs. It is possible that the proliferation of THP-1 is driven by multiple signaling pathways that are activated, thus no particular pathway is essential for its proliferation. This study suggests that signaling drug sensitivity profiling is a useful tool in combination with genomic and proteomic analyses in elucidating the oncogenic mechanism of a given cancer cell. 


\subsection{CTV-1 is a poorly understood AML cell line with some T-cell lymphoblastic leukemia}

characteristics

CTV-1 cell line was established as a human monocytoid leukemia cell line from a patient with relapsed monoblastic leukemia [23]. The cell can be induced to differentiate by the phorbolester 12-0-tetradecanoylphorbol 13-acetate treatment [24]. Surface marker analysis with 45 monoclonal antibodies and several polyclonal antisera and isoenzyme analysis of carboxylic esterase, acid phosphatase, and hexosaminidase and lactate dehydrogenase demonstrated CTV-1 to be of monocytoid origin arrested at a very early stage of differentiation [24].

The results clearly demonstrate a difference in the mechanism driving CTV-1 and THP-1 proliferation. While the difference could be related to the differences in their classification in M5a (CTV-1) and M5b (THP-1), in their degree of maturity (THP-1 being more mature), or

other developmental differences, it is more likely that the difference reflect the unique lineage of CTV-1. The lineage of CTV-1 is controversial and our results provide additional information on this controversy. After its initial establishment, various characterizations demonstrated CTV-1 to be an M5 type of AML [23-24]. A 2005 study by Andersson A. et al. examined the gene expression profiles of a large number of leukemia cell lines and patients, and identified the genomic and expression profiles of various types of leukemia [50]. It found that CTV-1 did not segregate with its leukemia type, AML. Instead, it segregated with the T-cell acute lymphoid leukemia, in that they share a common characteristic of Lck up-regulation. This observation has led to the question of the lineage of CTV-1 cells. Our results further expand on this observation and demonstrate that Lck is not only over-expressed in CTV-1 cells, it is actually the driver of CTV-1 proliferation. A study by Palomero T et al. [51] demonstrated that CTV-1 could also be an example of lineage switching, a rare but well documented phenomenon. Three (ML1, ML2, 
and CTV-1) of 23 AML cell lines they studied were derived from M5 AML relapse in patients initially diagnosed with T-cell acute lymphoblastic leukemia (T-ALL). All three cell lines contain activating NOTCH1 mutations that are frequently found in T-ALL cells. The molecular mechanism of lineage switching is not well understood, and if this hypothesis is true, CTV-1 would be a suitable cell model for investigating the molecular mechanisms of this phenomenon.

If the CTV-1 cell line is indeed is the product of a lineage switching initiated from a Tcell acute lymphoid leukemia, then the characteristics of the CTV-1 cells may not be representative of a typical M5 AML cell line. Further studies would be necessary to determine if this is the case.

\subsection{Lck and Src family kinases in cancer}

The Src family kinases have long been recognized to be potent oncoproteins and their activation is often associated with various human tumors. It is well established that Src family kinases constitutively activated either by mutation or overexpression cause cell transformation [52]. However, naturally occurring SFK activation by mutations as a cause of cancer is rare [5356]. This conclusion is also supported by recent genomic data of 1020 cancer cell lines. Only 26 Src coding mutations were discovered, and none have been shown to be responsible for driving proliferation. In contrast, the same set of cell lines contained 707 P53 mutations, 142 KRAS mutations, and 125 PTEN mutations. Despite the very low mutation rate, 112 samples displayed Src overexpression while only 15 displayed Src under-expression.

An examination of the Lck mutation and expression data provides an interesting perspective on the uniqueness of CTV-1 as an Lck driven cancer cell line. Out of 1020 cell lines, tested, only 33 contain Lck mutations and no amino acid mutation occurs more than once. Out of 
970 cell lines for which the Lck expression level has been determined, only 36 yield expression data, with 16 cell lines overexpressing Lck (Z-score > 2) and 20 under-expressing Lck (Z-score $<-2$ ). Of the 16 over-expressers, 14 are lymphoid cells and 2 are myeloid cells. CTV-1 is the highest over-expresser with a Z-score of 3.88. The reason majority of the cells did not yield data is likely due to the fact that those cells do not express Lck. Based on this reasoning, only lymphoid and myeloid blood cells appears to express Lck. The tissue distribution of Lck expression data is shown in Fig. 5. Based on this information, it appears that CTV-1 overexpressing and dependent on mutation-activated Lck is likely an uncommon mechanism. Nevertheless, this cell line can serve as a model system for investigating the biology of Src family kinases.

\section{Acknowledgements}

\section{Competing Interests}

The authors have no competing financial interests in relation to the work described.

\section{References}

1. Bennett JM, Catovsky D, Daniel MT, Flandrin G, Galton DA, Gralnick HR, et,al. Proposals for the classification of the acute leukaemias. French-American-British (FAB) co-operative group. Br J Haematol. 1976; 33:451-58.

2. DiNardo CD, Cortes JE. Mutations in AML: prognostic and therapeutic implications. Hematology Am Soc Hematol Educ Program. 2016;2016:348-55.

3. Takahashi S. Current findings for recurring mutations in acute myeloid leukemia. $\mathrm{J}$ Hematol Oncol. 2011;4:36. 
4. Ferrara F, Del Vecchio L. Acute myeloid leukemia with $t(8 ; 21) / A M L 1 / E T O:$ a distinct biological and clinical entity. Haematologica. 2002; 87:306-19.

5. Shigesada K, van de Sluis B, Liu PP. Mechanism of leukemogenesis by the inv(16) chimeric gene CBFB/PEBP2B-MHY11. Oncogene. 2004; 23: 4297-307.

6. Friedman AD. Leukemogenesis by CBF oncoproteins. Leukemia. 1999;13:1932-42.

7. De Braekeleer E, Douet-Guilbert N, De Braekeleer M. RARA fusion genes in acute promyelocytic leukemia: a review. Expert Rev Hematol. 2014;7:347-57.

8. Yokoyama A. Transcriptional activation by MLL fusion proteins in leukemogenesis. Exp Hematol. 2017;46:21-30.

9. Harper DP, Aplan PD. Chromosomal rearrangements leading to MLL gene fusions: clinical and biological aspects. Cancer Res. 2008;68:10024-7.

10. Shih AH, Abdel-Wahab O, Patel JP, Levine RL. The role of mutations in epigenetic regulators in myeloid malignancies. Nat Rev Cancer. 2012;12:599-612.

11. Kelly LM, Gilliland DG. Genetics of myeloid leukemias. Annu Rev Genomics Hum Genet. 2002;3:179-98.

12. Cancer Genome Atlas Research Network, Ley TJ, Miller C, Ding L, Raphael BJ, Mungall AJ, Robertson A, et,al. Genomic and epigenomic landscapes of adult de novo acute myeloid leukemia. N Engl J Med. 2013;368:2059-74.

13. Garcia JS, Stone RM. The Development of FLT3 Inhibitors in Acute Myeloid Leukemia. Hematol Oncol Clin North Am. 2017; 31(4):663-680.

14. Fernandez HF, Sun Z, Yao X, Litzow MR, Luger SM, Paietta EM, et,al. Anthracycline dose intensification in acute myeloid leukemia. N Engl J Med. 2009;361(13):1249-59. 
15. Douet-Guilbert N, Morel F, Le Bris MJ, Sassolas B, Giroux JD, De Braekeleer M. Rearrangement of MLL in a patient with congenital acute monoblastic leukemia and granulocytic sarcoma associated with a $\mathrm{t}(1 ; 11)(\mathrm{p} 36 ; \mathrm{q} 23)$ translocation. Leuk Lymphoma. 2005;46:143-6.

16. Chen Y, Kantarjian H, Pierce S, Faderl S, O'Brien S, Qiao W, et,al. Prognostic significance of 11q23 aberrations in adult acute myeloid leukemia and the role of allogeneic stem cell transplantation. Leukemia. 2013;27:836-42.

17. Bolen JB, Thompson PA, Eiseman E, Horak ID. Expression and interactions of the Src family of tyrosine protein kinases in T lymphocytes. Adv Cancer Res. 1991; 57:103-49.

18. Salmond RJ, Filby A, Qureshi I, Caserta S, Zamoyska R. T-cell receptor proximal signaling via the Src-family kinases, Lck and Fyn, influences T-cell activation, differentiation, and tolerance. Immunol Rev. 2009; 228:9-22.

19. Chiang GG, Sefton BM. Phosphorylation of a Src kinase at the autophosphorylation site in the absence of Src kinase activity. J Biol Chem. 2000;275:6055-8.

20. Abraham KM, Levin SD, Marth JD, Forbush KA, Perlmutter RM. Thymic tumorigenesis induced by overexpression of p561ck._Proc Natl Acad Sci U S A. 1991; 88:3977-81.

21. Adler HT, Sefton BM. Generation and characterization of transforming variants of the lck tyrosine protein kinase. Oncogene. 1992;7:1191-9.

22. Wright DD, Sefton BM, Kamps MP. Oncogenic activation of the Lck protein accompanies translocation of the LCKgene in the human HSB2 T-cell leukemia._Mol Cell Biol. 1994;14:2429-37.

23. Chen P, Chiu C, Chiou T, Maeda S, Chiang H, Tzeng C, et,al. Establishment and characterization of a human monocytoid leukemia cell line, CTV-1. Gan. 1984;75:660-4. 
24. Drexler HG, Gaedicke G, Maeda S, Chen PM, Minowada J. Monocytoid leukemia cell line CTV-1: morphological, immunological and isoenzymatic characteristics. Tumour Biol. 1986; 6:503-17.

25. Tsuchiya S, Yamabe M, Yamaguchi Y, Kobayashi Y, Konno T, Tada K. Establishment and characterization of a human acute monocytic leukemia cell line (THP-1). Int J Cancer. $1980 ; 26: 171-6$.

26. Auwerx J. The human leukemia cell line, THP-1: a multifacetted model for the study of monocyte-macrophage differentiation. Experientia. 1991;47:22-31.

27. Smith DB, Johnson KS. Single-step purification of polypeptides expressed in Escherichia coli as fusions with glutathione S-transferase. Gene. 1988 Jul 15;67(1):31-40.

28. Wittman MD, Carboni JM, Yang Z, Lee FY, Antman M, Attar R, et,al. Discovery of a 2,4-disubstituted pyrrolo[1,2-f][1,2,4]triazine inhibitor (BMS-754807) of insulin-like growth factor receptor (IGF-1R) kinase in clinical development. J Med Chem. 2009;52:7360-3.

29. Carboni JM, Wittman M, Yang Z, Lee F, Greer A, Hurlburt W, et,al. BMS-754807, a small molecule inhibitor of insulin-like growth factor-1R/IR. Mol Cancer Ther. 2009;8:3341-9.

30. Guagnano V, Furet P, Spanka C, Bordas V, Le Douget M, Stamm C, et,al. Discovery of 3-(2,6-dichloro-3,5-dimethoxy-phenyl)-1-\{6-[4-(4-ethyl-piperazin-1-yl)-phenylamino]pyrimidin-4-yl\}-1-methyl-urea (NVP-BGJ398), a potent and selective inhibitor of the fibroblast growth factor receptor family of receptor tyrosine kinase._J Med Chem. 2011; 54:7066-83. 
31. Futreal PA, Coin L, Marshall M, Down T, Hubbard T, Wooster R, Rahman N, Stratton MR. A census of human cancer genes. Nat Rev Cancer. 2004;4:177-83.

32. Beran M, Cao X, Estrov Z, Jeha S, Jin G, O'Brien S, Talpaz M, Arlinghaus RB, Lydon NB, Kantarjian H. Selective inhibition of cell proliferation and BCR-ABL phosphorylation in acute lymphoblastic leukemia cells expressing Mr 190,000 BCR-ABL protein by a tyrosine kinase inhibitor (CGP-57148). Clin Cancer Res. 1998; 4:1661-72.

33. Cooper JA, Howell B. The when and how of Src regulation. Cell. 1993;73:1051-4.

34. Roskoski R Jr. Src protein-tyrosine kinase structure, mechanism, and small molecule inhibitors. Pharmacol Res. 2015; 94:9-25.

35. Burchat A, Borhani DW, Calderwood DJ, Hirst GC, Li B, Stachlewitz RF. Discovery of A-770041, a src-family selective orally active lck inhibitor that prevents organ allograft rejection._Bioorg Med Chem Lett. 2006;16:118-22.

36. Stachlewitz RF, Hart MA, Bettencourt B, Kebede T, Schwartz A, Ratnofsky SE, et,al. A770041, a novel and selective small-molecule inhibitor of Lck, prevents heart allograft rejection._J Pharmacol Exp Ther. 2005;315:36-41.

37. Martin MW, Newcomb J, Nunes JJ, McGowan DC, Armistead DM, Boucher C, et,al. Novel 2-aminopyrimidine carbamates as potent and orally active inhibitors of Lck: synthesis, SAR, and in vivo antiinflammatory activity. J Med Chem. 2006;49:4981-91.

38. Sondka Z, Bamford S, Cole CG, Ward SA, Dunham I, Forbes SA. The COSMIC Cancer Gene Census: describing genetic dysfunction across all human cancers. Nat Rev Cancer. 2018 Nov;18(11):696-705. doi: 10.1038/s41568-018-0060-1. Review. 
39. Ben-Bassat H, Korkesh A, Voss R, Leizerowitz R, Polliack A.Establishment and characterization of a new permanent cell line (GDM-1) from a patient with myelomonoblastic leukemia. Leuk Res. 1982;6(6):743-52.

40. Songyang Z, Carraway KL 3rd, Eck MJ, Harrison SC, Feldman RA, Mohammadi M, Schlessinger J, Hubbard SR, Smith DP, Eng C, et al. Catalytic specificity of proteintyrosine kinases is critical for selective signalling. Nature. 1995;373:536-9.

41. Gonfloni S, Williams JC, Hattula K, Weijland A, Wierenga RK, Superti-Furga G. The role of the linker between the SH2 domain and catalytic domain in the regulation and function of Src._EMBO J. 1997;16:7261-71.

42. Sicheri F, Moarefi I, Kuriyan J. Crystal structure of the Src family tyrosine kinase Hck. Nature. 1997; 385:602-9.

43. Xu W, Doshi A, Lei M, Eck MJ, Harrison SC. Crystal structures of c-Src reveal features of its autoinhibitory mechanism. Mol Cell. 1999; 3:629-38.

44. Alvarado JJ, Betts L, Moroco JA, Smithgall TE, Yeh JI. Crystal structure of the Src family kinase Hck SH3-SH2 linker regulatory region supports an SH3-dominant activation mechanism._J Biol Chem. 2010; 285:35455-61.

45. Gonfloni S, Frischknecht F, Way M, Superti-Furga G. Leucine 255 of Src couples intramolecular interactions to inhibition of catalysis. Nat Struct Biol. 1999; 6:760-4.

46. Lee S, Lin X, Nam NH, Parang K, Sun G. Determination of the substrate-docking site of protein tyrosine kinase C-terminal Src kinase._Proc Natl Acad Sci U S A. 2003; 100:14707-12. 
47. Lee S, Ayrapetov MK, Kemble DJ, Parang K, Sun G. Docking-based substrate recognition by the catalytic domain of a protein tyrosine kinase, $\mathrm{C}$ terminal Src kinase (Csk). J Biol Chem. 2006;281:8183-9.

48. Levinson NM, Seeliger MA, Cole PA, Kuriyan J. Structural basis for the recognition of c-Src by its inactivator Csk. Cell. 2008;134:124-34.

49. Duan Z, Zhang J, Ye S, Shen J, Choy E, Cote G, Harmon D, Mankin H, Hua Y, Zhang Y, Gray NS, Hornicek FJ. A-770041 reverses paclitaxel and doxorubicin resistance in osteosarcoma cells. BMC Cancer. 2014;14:681.

50. Andersson A, Edén P, Lindgren D, Nilsson J, Lassen C, Heldrup J, Fontes M, Borg A, Mitelman F, Johansson B, Höglund M, Fioretos T. Gene expression profiling of leukemic cell lines reveals conserved molecular signatures among subtypes with specific genetic aberrations. Leukemia. 2005;19:1042-50.

51. Palomero T, McKenna K, O-Neil J, Galinsky I, Stone R, Suzukawa K, et,al. Activating mutations in NOTCH1 in acute myeloid leukemia and lineage switch leukemias. Leukemia. 2006;20:1963-6.

52. Kim LC, Song L, Haura EB. Src kinases as therapeutic targets for cancer. Nat Rev Clin Oncol. 2009;6:587-95.

53. Laghi L, Bianchi P, Orbetegli O, Gennari L, Roncalli M, Malesci A. Lack of mutation at codon 531 of SRC in advanced colorectal cancers from Italian patients. Br J Cancer. 2001; 84:196-8.

54. Nilbert M, Fernebro E. Lack of activating c-SRC mutations at codon 531 in rectal cancer. Cancer Genet Cytogenet. 2000;121:94-5. 
55. Daigo Y, Furukawa Y, Kawasoe T, Ishiguro H, Fujita M, Sugai S, et,al. Absence of genetic alteration at codon 531 of the human c-src gene in 479 advanced colorectal cancers from Japanese and Caucasian patients. Cancer Res. 1999;59:4222-4.

56. Irby RB, Mao W, Coppola D, Kang J, Loubeau JM, Trudeau W, et,al. Activating SRC mutation in a subset of advanced human colon cancers. Nat Genet. 1999;21:187-90. 


\section{Figure 1}

Click here to download high resolution image

Li et al. Fig. 1. Dose response curves of CTV-1 and THP-1 cell proliferation to protein tyrosine kinase inhibitors.

$1 \mathrm{~A}$

CTV-1 THP-1

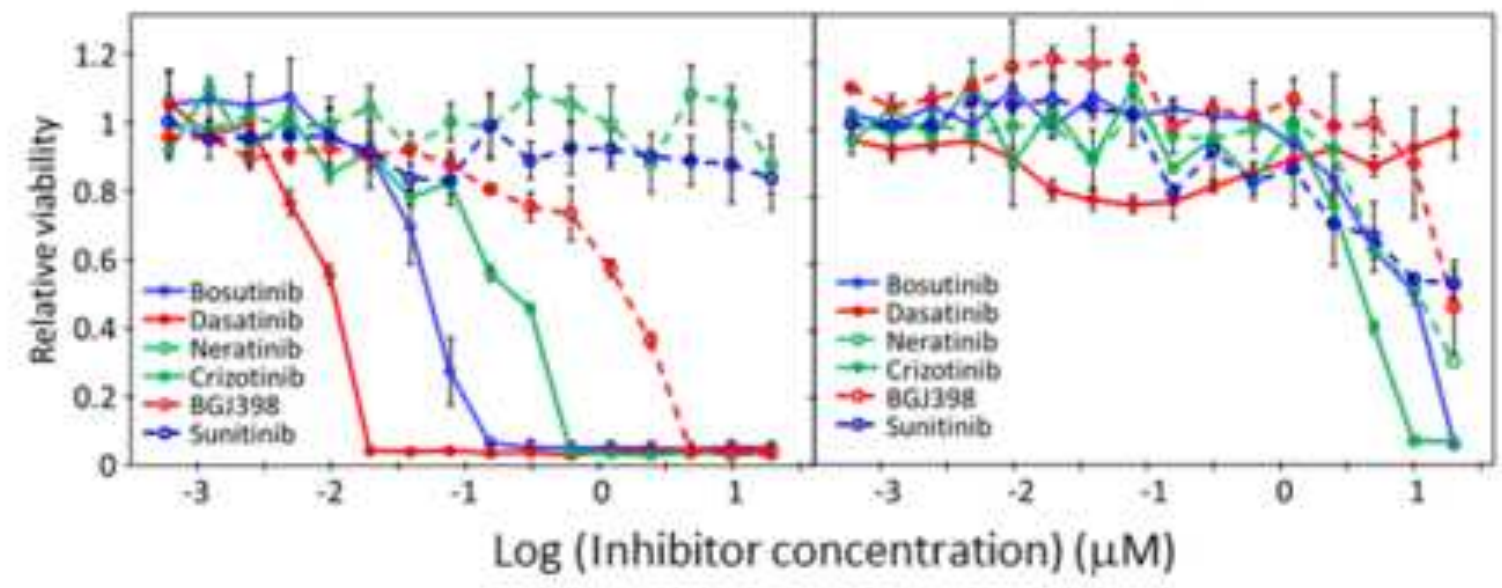

1B

CTV-1

THP-1

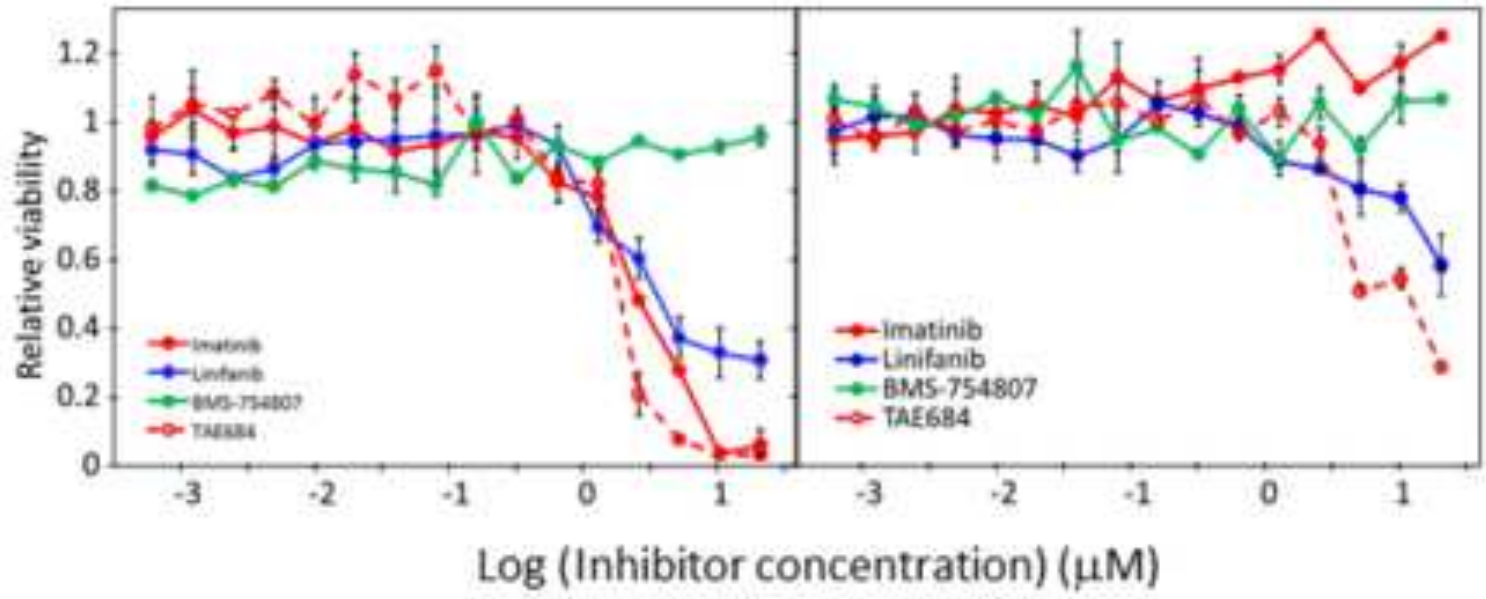


Click here to download high resolution image

Li et al. Fig. 2. Inhibition of CTV-1 cell proliferation by Lek-specific inhibitors and Lck expression in three AML cell lines.

Fig. 2A

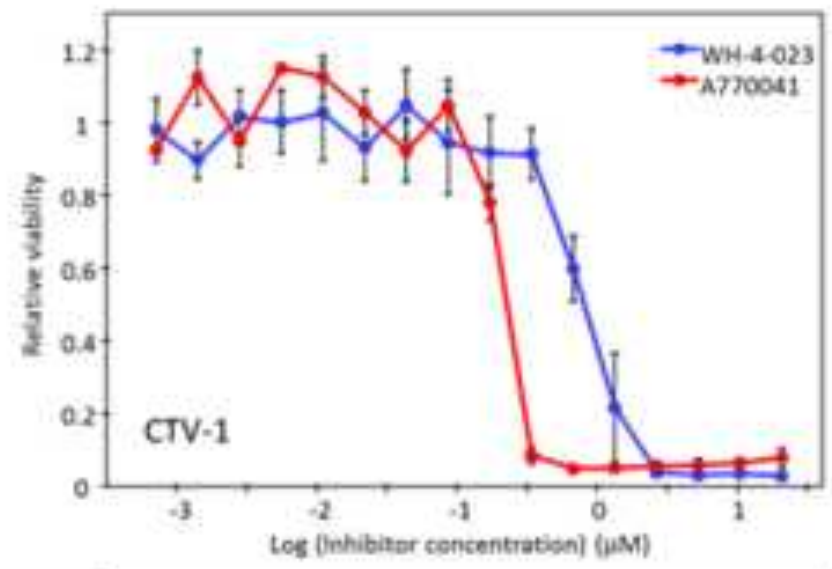

Fig. 2B

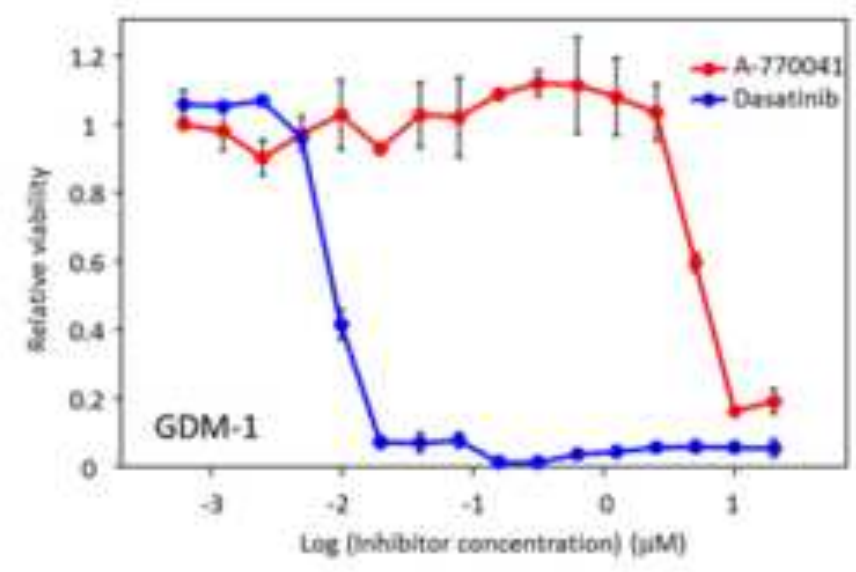

Fig. 2C

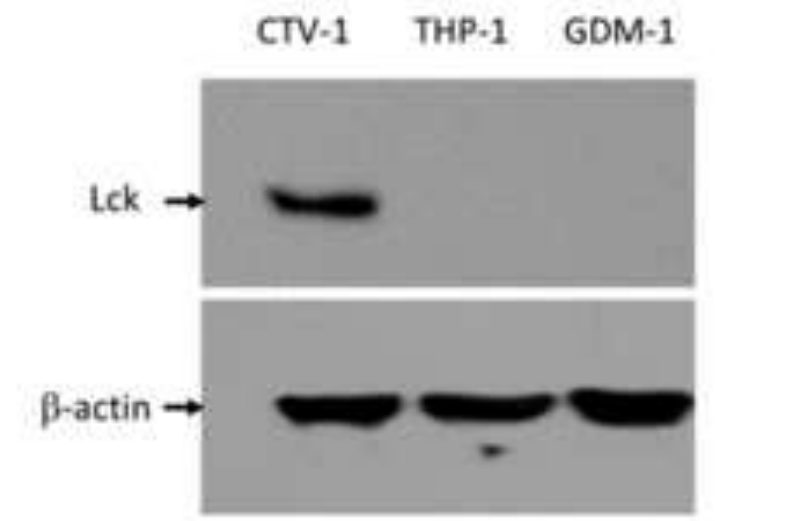


Click here to download high resolution image

Li et al. Fig. 3. Phosphorylation of an Lck peptide substrate by CTV-1 and THP-1 cell lysates.

Fig. 3A

\begin{tabular}{|c|c|c|c|c|c|c|c|}
\hline CTV-1 lys: & + & + & + & + & + & + & + \\
\hline Lck sub: & - & + & - & + & - & + & . \\
\hline Dasatinib: & - & - & + & + & - & - & 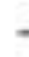 \\
\hline A770041: & - & - & - & - & - & - & + \\
\hline
\end{tabular}

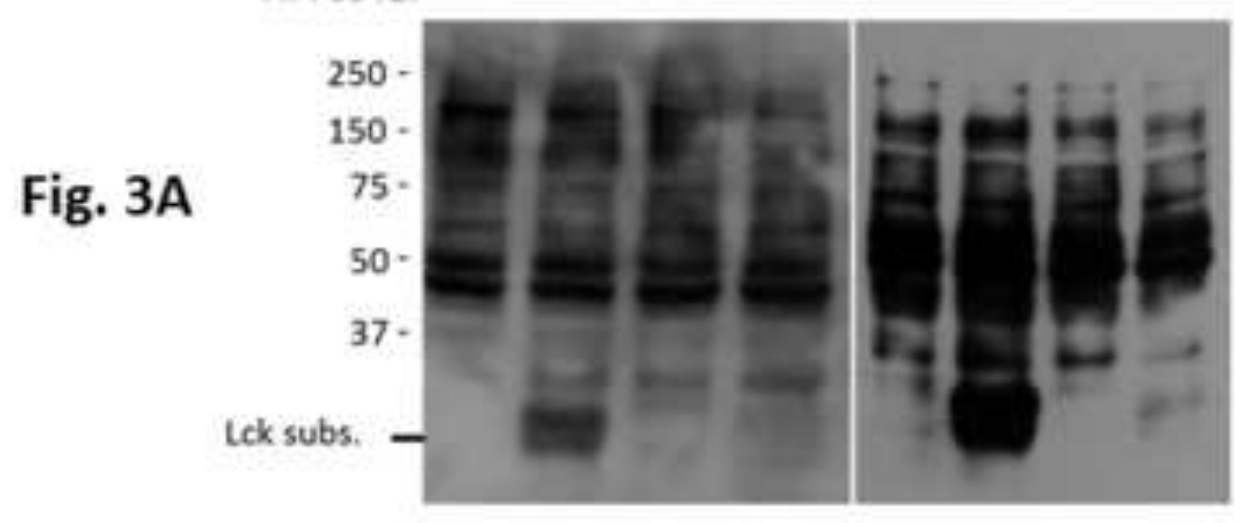

Fig. 3B

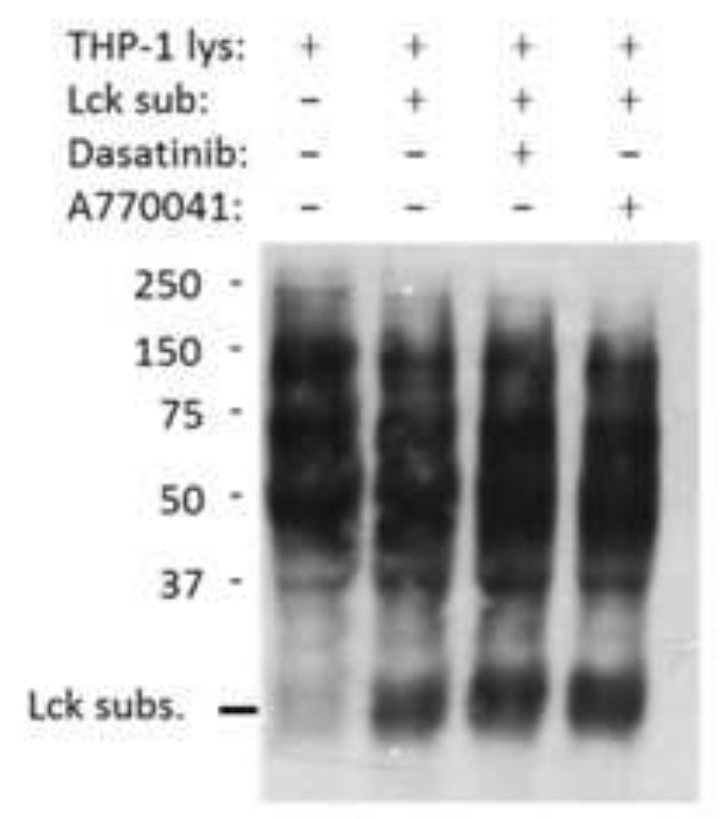


Click here to download high resolution image

Li et al. Fig. 4. Kinase activity of wt Lck and the effects of CTV-1 mutations on Lck activity.

Fig. 4A

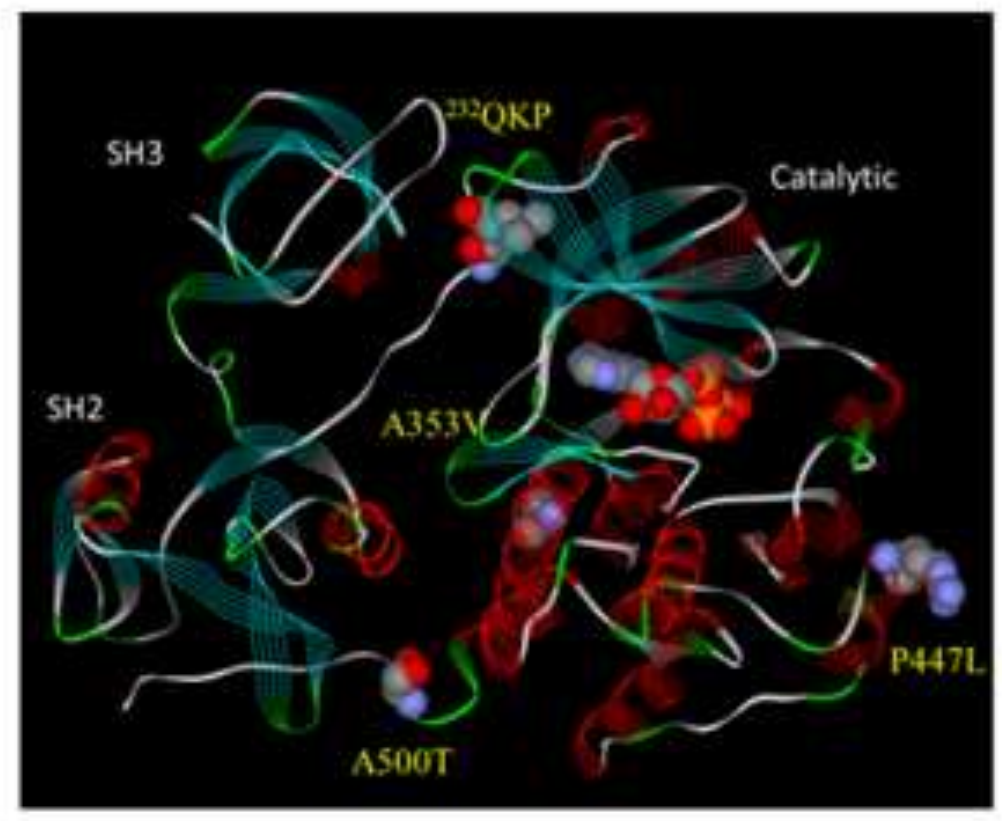

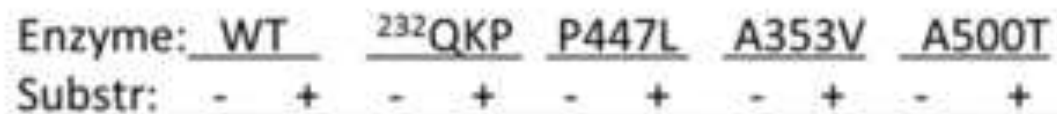

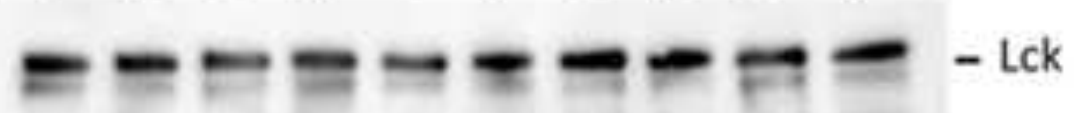

Fig. 4B

- Lck subs.

Fig. 4C

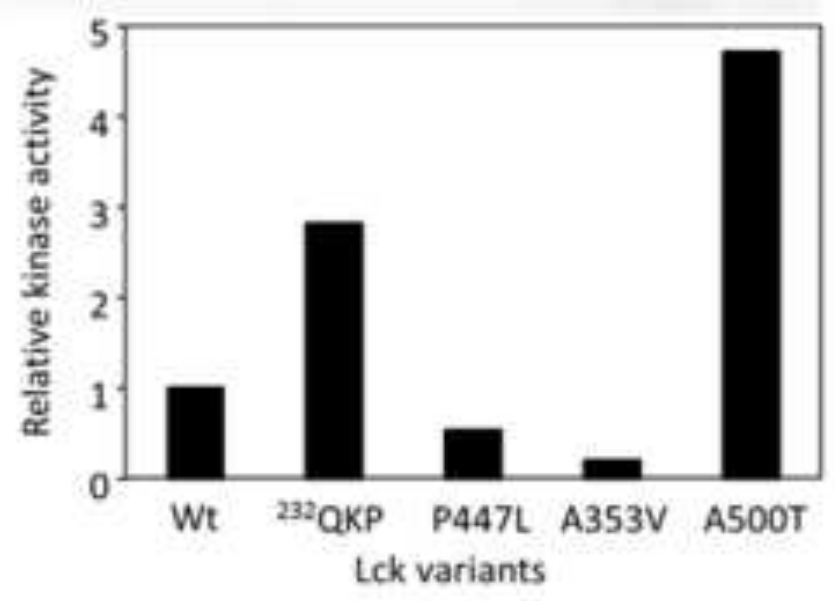


Figure 5
Click here to download high resolution image

Li et al. Fig. 5. Lck expression level in cancer cell lines from different tissues.

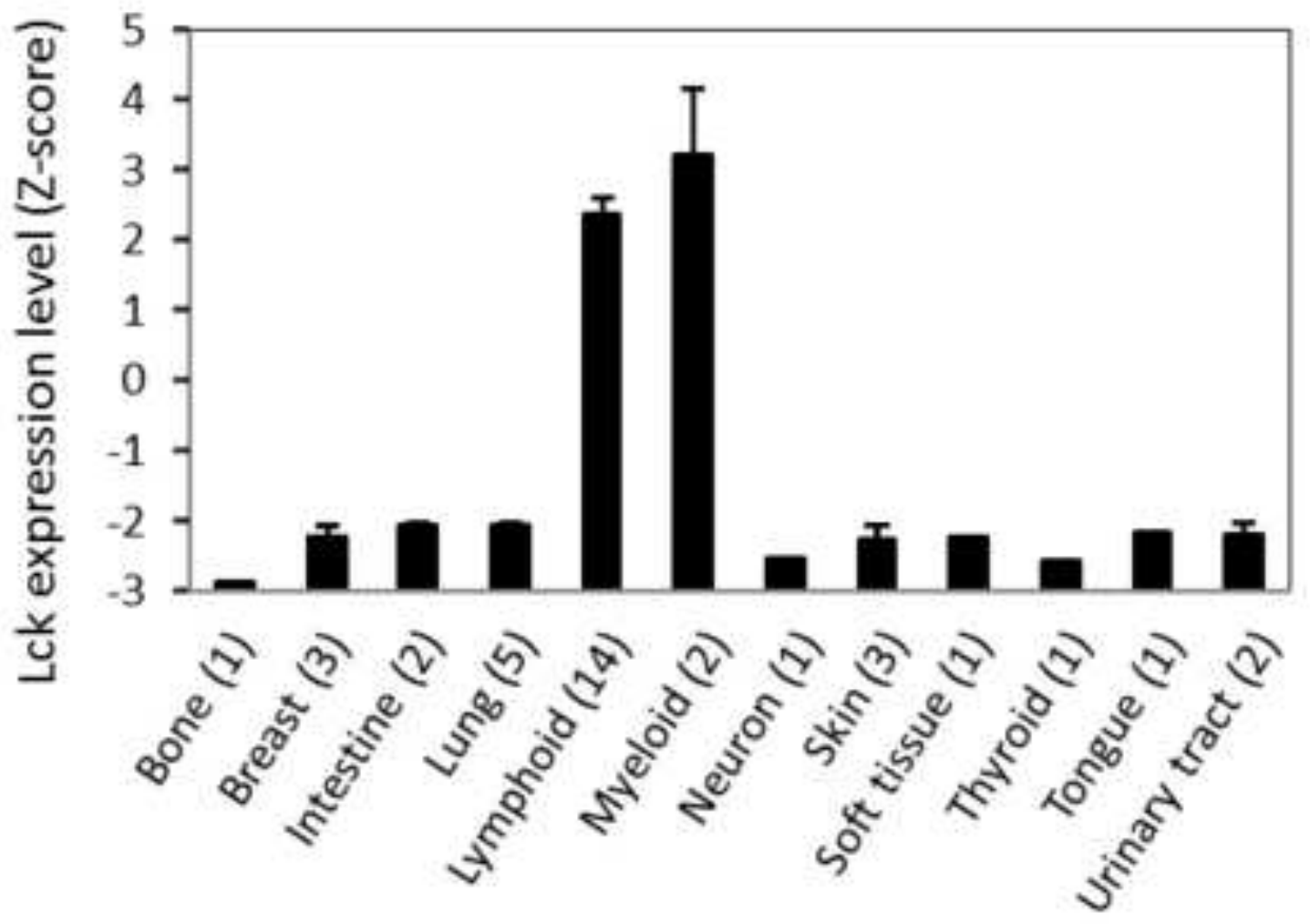




\section{Figure legends:}

Fig. 1. Dose response curves of CTV-1 and THP-1 cell proliferation to protein tyrosine kinase inhibitors. Cell proliferation assay was performed as described in Materials and Methods. The cell viabilities after 72-h incubation in the presence of $0.0006-20 \mu \mathrm{M}$ of PTK inhibitors were determined by staining cells with Biolog Redox dye as described. For easy comparison, the CTV-1 and THP-1 responses to the same set of drugs are presented side by side. For purpose of clarity, the ten drugs tested were presented in two panels 1A and 1B. The inhibitors and their binding affinity toward cancer census PTKs are detailed in Table 1.

Fig. 2. Inhibition of cell proliferation by Lck-specific inhibitors and Lck expression in AML cells. A. Inhibition of CTV-1 cell proliferation by Lck-specific inhibitors, A-770041 and WH-4023. The cells were incubated with a series of drug concentrations for $72 \mathrm{~h}$, before the cell viability was determined using Biolog Redox Mix A. B. Inhibition of GDM-1 cell proliferation by dasatinib and A-770041. C. Lck expression in CTV-1, THP-1 and GDM-1 detected by Western blot. The antibody used is specific for Lck. Each lane contained cell lysate from approximately $6.25 \times 10^{6}$ cells. $\beta$-actin expression level as a control was detected by a $\beta$-actin specific antibody.

Fig. 3. Phosphorylation of an Lck peptide substrate by CTV-1 and THP-1 cell lysates. The ability of CTV-1 (A) or THP-1 (B) cell lysates to phosphorylate an Lck-specific peptide substrate and the sensitivity of this activity to inhibition by Lck inhibitors were determined. The Lck peptide substrate was expressed as a fusion protein at the C-terminal end of glutathione Stransferase. The cell lysate were incubated with the purified Lck peptide substrate for 30 min 
under phosphorylating conditions in the presence or absence of the Lck inhibitors. The total proteins from the phosphorylation reactions were fractionated by SDS-PAGE, and proteins phosphorylated on Tyr were detected by Western Blotting using an antibody for phosphotyrosine. The Lck inhibitors dasatinib and A-770041 at $1 \mu \mathrm{M}$ were included as indicated.

\section{Fig. 4. Kinase activity of wt Lck and the effects of CTV-1 mutations on Lck activity. A.} Ribbon structure of Src, illustrating the position of the four Lck mutations found in CTV-1 cells. The Src structure was generated from the Src structure coordinates (PDB ID: 2Src) [43] using the Discovery Studio Visualizer. The overall structures of Lck and Src are similar. B. The effects of CTV-1 mutations on Lck kinase activity. The full length human Lck coding sequence was cloned into pGEX-4T-1, and was expressed as a GST-Lck fusion protein. Mutations found in CTV-1 Lck were introduced into the pGEX-Lck. The wt and mutant Lck variants were expressed in E. coli strain DH5 $\alpha$ and purified as GST fusion proteins. The kinase activity of the purified

proteins was determined by Western Blotting as described in Materials and Methods. C. Relative kinase activities of wt and mutant Lck. The relative activities were determined by subtracting control (no peptide lanes) from the peptide substrate band density. The band density was measured by ImageJ software.

Fig. 5. Lck mRNA expression levels in cancer cells from different tissues. The Z-scores were plotted as a function the origin of the cell lines. The numbers in parentheses after the names of the tissue indicate the number of cell lines the data is derived from. Standard deviations of the Zscores in each group were presented. The data was obtained from Catalogue of Somatic Mutations in Cancer (https://cancer.sanger.ac.uk/cell_lines/sample/overview?id=753548). In the 
study, the Lck expression was examined in 1020 cell lines. Sixteen cell lines displayed overexpression, while 20 cell lines displayed under-expression. 
Table 1. Primers used for generating the Lck mutants

\begin{tabular}{|c|c|}
\hline P232insCCCAGAAGC Primer $(+)$ & cctTGCcagaCCCAGAAGCcGcaAaaAcCCCAGAAaCCATGGTGG \\
\hline P232insCCCAGAAGC Primer (-) & CCACCATGGtTTCTGGGgTttTtgCgGCTTCTGGGtctgGCAagg \\
\hline A353V Primer $(+)$ & ATTGCAGAGGGCATGGtGTTCATCGAAGAACAG \\
\hline A353V Primer (-) & CTGTTCTTCGATGAACaCCATGCCCTCTGCAAT \\
\hline P447L Primer $(+)$ & CCAGGAATGACCAACCtTGAAGTCATTCAGAACC \\
\hline P447L Primer (-) & GGTTCTGAATGACTTCAaGGTTGGTCATTCCTGG \\
\hline A500T Primer (+) & GATGACTTCTTCACAaCCACAGAGGGCCAGTACC \\
\hline A500T Primer $(-)$ & GGTACTGGCCCTCTGTGGtTGTGAAGAAGTCATC \\
\hline
\end{tabular}


Table 2. Protein tyrosine kinase inhibitors used in this study.

\begin{tabular}{ll}
\hline Inhibitor & Target kinases $\left(K_{d}\right.$ in nM)* \\
\hline BGJ398 & FGFR1 $(0.9)$, FGFR2 (1.4), FGFR3 (1), FGFR4 (60) \\
BMS-754807 & IGF1-R (1.8), insulin receptor (1.7), Met (5.6) \\
Bosutinib & $\begin{array}{l}\text { Abl1 (0.12), Abl2 (1.5), EGFR3 (0.77), EphA3 (5.8), Lck (0.59), Src (1), BTK } \\
(4.8)\end{array}$ \\
Crizotinib & Alk (3.3), Met (2.1), Lck (30) \\
Dasatinib & Abl1 (0.03) Abl2 (0.17), PTK6 (7.8), EGFR3 (18), EphA3 (0.09), CSF1R (0.58), \\
& Kit (0.81), PDGFRA (0.47), PDGFRB (0.63), Lck (0.2), Src (0.21), Btk (1.4) \\
Imatinib & Abl1 (1.1), Abl2 (10), CSF1R (11), Kit (13), PDGFRB (14) \\
Linifanib & CSF1R (3.4), FLT3 (0.6), Kit (02), PDGFRA (4.2), PDGFRB (1.9), FLT4 (16), \\
& VEGFR2 (8.1) \\
Neratinib & EGFR1 (1.1), EGFR2 (6), EGFR3 (7.7), EGFR4 (2.4) \\
Sunitinib & CSF1R (2.5), FLT3 (0.4), Kit (0.4), PDGFRA (0.8), PDGFRB (0.1), Ret (13), \\
& ITK (13), VEGFR2 (1.5) \\
TAE684 & Alk (1.1), Fes (4.8), Jak2 (16), Jak3 (17), FLT3 (15)
\end{tabular}

*The target cancer census PTKs with $K_{d}$ values below $20 \mathrm{nM}$ are listed for each inhibitor. The number in the parenthesis following each PTK is the $K_{d}$ in nM. 


\section{${ }^{\star}$ Acknowledgements}

\section{Acknowledgements}

Financial support for this work from the College of Environment and Life Sciences at the University of Rhode Island is acknowledged. Dr. Li Li and Ms. Jinyan Shen are supported by scholarships from the Shanxi Medical University, Taiyuan, China. 


\section{Statements of conflict of interest}

The authors have no financial or other conflict of interest with the research reported in this paper. 
Evidence for activated Lck protein tyrosine kinase as the driver of proliferation in acute myeloid leukemia cell, CTV-1

$\mathrm{Li} \mathrm{Li}^{1,2}$, Yixin $\mathrm{Cui}^{2}$, Jinyan Shen ${ }^{1,2}$, Hannah Dobson ${ }^{2}$ and Gongqin Sun ${ }^{1,2^{*}}$

${ }^{1}$ Department of Cell Biology and Medical Genetics, School of Basic Medical Science, Shanxi Medical University, Taiyuan, Shanxi, China

${ }^{2}$ Department of Cell and Molecular Biology, University of Rhode Island, Kingston, RI, USA.

*Correspondence should be addressed to:

Gongqin Sun,

Department of Cell and Molecular Biology,

University of Rhode Island

120 Flagg Road, Kington, RI 02881

Telephone: 401-874-5937, email: gsun@uri.edu

Running title: Lck as a proliferative driver of AML cell, CTV-1

Key words: acute myeloid leukemia, Lck protein tyrosine kinase, driver mutations, driver of proliferation, CTV-1 